\title{
Природные мотивы в романе Владимира Набокова «Дар», как средство деавтоматизации
}

\section{Natural Motifs in the Novel by Vladimir Nabokov The Gift as the Recource of Deautomation}

\author{
Зденек Пехал \\ (Оломоуц, Чешская Республика)
}

\begin{abstract}
:
On one side of the opposition in the novel The Gift there is the area of mechanical-gray existence, a black-and-white mechanism that kills all sorts of mobility and variety. Before the reader is the line of the order closed in a circle of automatism (an alien, an emigrant in Berlin). And on the other hand, the opposition outlines the image of something mobile, still unnamed, spontaneous, without any authority, which leads to the deautomation of the world and life and transfers the meaning to something unexpected, unknown. The natural images of Asia support those lines of the novel The Gift which are based on playfulness, understatement, mystery, ambiguity, mobility, metamorphosis, spontaneity, unprespeakability, multi-image. The natural motifs form not only an exotic environment, but, above all, a new, just giving rise to a perception of reality as a mystery, something vague and constantly changing. Through these ambiguity images the protagonist personifies himself. In the novel The Gift the variable face of reality and illusion of reality occupies the important place. And this interaction of reality, fantasy and illusion is caused by the all-present principle of the game. That is the point we would like to emphasize in understanding the Asiatic motifs of the novel The Gift. Natural motifs are included in that part of the figurative system of Nabokov's novels which create the idea of novel's reality as infinitely born diverse alternative. The novel here takes the form of multifaceted thinking about mirages, dualism, mimicry, variability and mobility. Through the principle of constantly hinting and emerging alternatives, the eternally disconnected reality of the human world is paradoxically united.
\end{abstract}




\section{Key words:}

Vladimir Nabokov; The Gift; natural motifs; the mechanical area of the novel; spontaneous and dualism area of the novel; principle of deautomatization in the novel

Роман Владимира Набокова «Дар» состоит из пяти частей. В романе «Дар» скрещиваются две концепции мира: одна - восходящая к прочно установленной структуре закона, иерархии, автоматизме восприятия, и другая концепция - фантазия, стихийность, многообразие, подвижность. Образы азиатской природы включены в главу вторую и они поддерживают вторую концепцию - особое, творчески неограниченное восприятие мира. В нашей статье мы попытаемся описать мотивы из азиатского путешествия и дать их интерпретацию в рамках композиционного состава романа «Дар».

Первая глава открывается повествованием главного героя Федора Годунова-Чердынцева. Он живет в Берлине и все здесь для него является чужим. В вводной главе читатель имеет возможность впервые встретиться со сложной формой повествования [TAMMI 1985], когда Годунов-Чердынцев разговаривает с воображаемым собеседником - поэтом Кончеевым. Воображаемый разговор чередуется с воспоминаниями. В воспоминаниях настоящее время переплетается с прошлым и на этой основе создается сложное впечатление времени, которое можно определить как настоящее прошлого. Диалог с будущим или с возможным будущим образует настоящее будущего. Таким образом, на протяжении всего романа создается сложное впечатлиние времени, в котором переплетается настоящее с прошлым и будущим. Годунов-Чердынцев представлен в первой главе в роли эмигранта. Годунов-Чердынцев воспринимает берлинский мир как что-то чуждое [PECHAL 1999, 49-98; DOLININ 2004, 231-267]. С этой чуждостью контрастирует реальность его детства, идиллическое пространство-время, существующее лишь в форме иллюзорных воспоминаний. И этот диалог с родным дается посредством его сборника стихотворений, о котором идет речь в разговоре с воображаемым Кончеевым. Как оппозиция к «мелодии прошлого» дается «чуждое» Берлина. Глава первая - это реальная встреча с чуждым. Приведенная чуждость нашла, например, свое воплощение и в бездарном и смешном драматическом произведении-трагедии ришского немца Баха (Буша). Пародийность и курьезность произведения подчеркнута трагикомическим чтецом - автором, который с серьезным лицом произносит слова трагедии на собрании родных эмигрантов. Трагическая линия первой части романа подчеркнута излишней смертью Яши Чернышевского. В этом 
случае многообразие жизни как бы сузилось на черно-белое видение, из которого вытекает мысль о безысходном положении человека среди мира как экзистенциальной чужбины. Единственным выходом из безнадежного положения является самоубийство и смерть. Результатом черно-белого видения является ненужная смерть молодого человека. Многообразие мира здесь столкнулось с однообразным видением и трагическим черно-белым толкованием действительности. Этот мотив найдет свое продолжение и в следующих главах романа.

Вторая глава начинается богатым воображением рая.

«Отец однажды, в О́рдосе, (и здесь уже начинаются природные образы 3.П.), поднимаясь после грозы на холм, ненароком вошел в основу радуги, редчайший случай! - и очутился в цветном воздухе, в играющем огне, будто в раю. Сделал еще шаг - и из рая вышел» [NABOKOV 2000, 261].

Вторая глава, таким образом, связана с образом отца, известным энтомологом. На первый план выходит многогранный характер отца, его талант и многообразие мышления.

«Он был наделен ровным характером, выдержкой, сильной волей, ярким юмором; когда же он сердился, гнев его был как внезапно ударивший мороз... [...] Он, перебивший на своем веку тьму тьмущую птиц... [...] не мог мне простить лешенского воробья, подстреленного мной из монтекристо... [...] Он не терпел мешканья, неуверенности, мигающих глаз лжи, не терпел ничего приторного и притворного, - и я уверен, что уличи он меня в физической трусости, то меня бы он проклял... [...] Он был счастлив среди еще недоназванного мира, в котором он при каждом шаге безымянное именовал.» [NABOKOV 20оо, 297-303].

Волшебство природного образа в видении Годунова-Чердынцева связано с волшебством слова Пушкина. Годунов-Чердынцев воображает отца и его путешествия и, чтобы выразить все в словах, он «вслушивался в чистейший звук пушкинского камертона». Вторая часть романа основана на воображаемом путешествии по Азии, на волшебных природных образах и на впечатлении от мастерства пушкинского слова. Его отец был не только знаменитый естествоиспытатель и путешественник, коллекционер бабочек, но прежде всего образец творческой личности. Книгу об отце Годунов-Чердынцев очень хотел написать, но так и не смог сделать этого. Попытка создать равноценную действительности словесную картину прошлого осталась нереализованной. Книга осталась ненаписанной.

Если вторая глава связана с отцом и написана с учетом талантливости, одаренности, человеческой неограниченности, творческой широты и безграничной изобретательности и находчивости, то четвертая глава, часть о Чернышевском, 
является ее оппозицией. Роман был опубликован в пяти номерах парижского альманаха «Современные записки» (№ 63-67 в 1937-1938 годах). Резкий тон четвертой главы, посвященной Чернышевскому, стал причиной того, что в первом издании романа эта глава была пропущена. В главе о Чернышевском преобладает серость и бесцветность, все здесь однообразно, скучно - «святая ненаблюдательность (а отсюда - полная неосведомленность об окружающем мире - и полная неспособность что-либо именовать)». В пародийной интерпретации жизни Чернышевского преобладает заурядность и недюжинность, неестественность и организованность. Характеристика Чернышевского дается в издевательски-карикатурном, нарочито гипертрофированном виде. Игривая и фантазией наполненная вторая глава чередуется с главой четвертой, которую можно считать ее смысловой оппозицией.

Третья глава является исключением среди несюжетных глав. Третья глава завязывает и постепенно раскрывает самую главную линию романного настоящего времени - отношения Годунова-Чердынцева и Зины Мерц. Отношения Зины и Годунова-Чердынцева становятся с развитием сюжета видными, и, прежде всего, посредством возникающих ситуаций выявляется новое лицо Годунова-Чердынцева, которое пытается возобновить среди чуждого Берлина надежду на реальное жизненное многообразие. До сих пор он выступает в роли не очень известного поэта. У него есть представления о самом высоком уровне словесного искусства (судя по воображаемым разговорам с Кончеевым), но осуществить их нелегко. Даже его мать Елизавета Павловна, которая посетила его в Берлине, хотела больше всего узнать, как русская среда в Берлине относится к стихам Федора и почему о них никто не пишет. И его выступление на литературном вечере после гениального Кончеева осталось почти незамеченным.

«Федор Константинович с тяжелым отвращением думал о стихах, по сей день им написанных, о словах-щелях, об утечке поэзии, и в то же время с какой-то радостной, гордой энергией, со страстным нетерпением, уже искал создания чего-то нового, еще неизвестного, настоящего полностью отвечающего дару, который он как бремя чувствовал в себе.» [NABOKOV 2000, 277].

Хотя стихи неплохие, Федор понимает, что они не представляют то настоящее, что он от них ожидает и что могло бы отвечать его представлениям о настоящем даре. Постоянно возвращается мотив ключей, когда человек по разным причинам находится перед закрытой дверью, дверь нельзя открыть и из-за этого препятствия нельзя сделать решительный шаг.

В связи с Зиной опять появляется надежда на что-то жизненно настоящее. В сером Берлине появляется островок чего-то исключительного, с чем Годунов-Чердынцев связывает надежду на будущее. Таким образом, у Годунова- 
-Чердынцева есть две возможности, как возобновить потерянный рай: с одной стороны, воспользоваться даром и создать настоящее искусство - мастерское прозведение. И, с другой стороны, найти близкого человека, с которым он мог бы возобновить потерянный многообразный мир и создать что-то жизненно настоящее.

Таким образом, Годунов-Чердынцев находится в ситуации сложных противоречий и дилемм. С одной стороны, это его утрата настоящего мира навсегда потерянной дореволюционной России, а с другой стороны, берлинская чужбина. Дилемма воображаемого дара и идеала его дарования, с одной стороны, и постояное ускользание от усовершествования дара, с другой стороны. Чувствуется постоянная неспособность и невозможность написать произведение, которое бы полностью отвечало его дару. Перед глазами Годунова-Чердынцева постоянно обнаруживается одновременно приближающийся и удаляющийся женский образ. Таким образом, женский образ двоится между реальностью и иллюзией. Постоянно появляются препятствия совместной жизни, то в виде потерянных ключей, то в виде иллюзорных надежд вместо реальности. В романе в связи с Годуновым-Чердынцевым постоянно присутствуют вариации темы смерти и конца человеческого существования. Смерть сначала представлена в образе ненужного самоубийства Яши и потом продолжается в незаконченном образе смерти отца, пропавшего без вести. Смерть отца связана с постоянной надеждой, что он где-то живет. Часто встречающийся образ смерти вносит в роман постоянно звучающий вопрос: кто виноват? В чем заключается причина сегодняшнего берлинского серого существования?

Таким образом, все постоянно двоится между реальностью и мечтой, воображением, иллюзией. Способом повествования главный герой постоянно двоитюя между «я» и «не я». [FICHTE 2007, 34-36; PECHAL 2011, 14; DOLININ 2004, 306-307]. Контрадикция «я» и «не я» точно выражает постоянное просачивание субъекта и объекта. Субъект в течение творческой деятельности полностью отождествляется с объектом и, таким образом, с одной стороны, теряет самого себя, а, с другой стороны, одновременно конституирует новое «я», неясное, не четко нащупываемое и постоянно исчезающее и убегающее от него.

«Мне иногда кажется теперь, что, как знать, может быть, удаляясь в свои путешествия, он не столько чего-то искал, сколько бежал от чего-то, а затем, возвратившись, понимал, что оно все еще с ним, в нем, неизбывное, неисчерпаемое. Тайне его я не могу подыскать имени, но только знаю, что оттого то и получалось то особое - и не радостное, и не угрюмое, вообще никак не относящееся к видимости жизненных чувств, - одиночество.» [NABOKOV 200о, 298] 
«Исследовав тибетские нагорья, я пошел на Лоб-Нор, чтобы уже оттуда возвратиться в Россию. Тарым, одолеваемый пустыней, изнемогая, из самых последних вод образует обширное тростниковое болото, нынешний Кара-Кошук-Куль, Лоб-Нор Пржевальского...» [NABOKOV 2000, 277].

На основе этих примеров можно заметить постоянное просвечивание точки зрения «я» и «он», он - в смысле «не я». Таким образом, можно сказать, что в природные мотивы Набоковым включены самые серьезные эстетические и ценностные аспекты его романа «Дар» и, в целом, всего его творчества. Будут приведены только некоторые примеры с целью показать видение среды Асии двойным зрением и Годунова-Чердынцева («я»), и видением отца («не-я»). В этих примерах будут подчеркнуты те аспекты, которые важны для эстетического видения Владимира Набокова и его ценностной иерархии.

Пример многообразного видения действительности в ее подвижности, незаконченности и постоянной изменчивости. Просвечивание образов, связанных с видением мира как игры, в течение которой все переживает постоянное движение и изменчивость. Объект действительности сливается с его отражением и посредством игрового взаимодействия разных полюсов художественного восприятия образуется новая действительность романа.

«Только в Китае ранний туман так обаятелен, все дрожит, - фантастические очерки фанз, светающие скалы... Точно в пучину, уходит река во мглу предутренних сумерек, которые еще держатся в ущельях; а повыше, вдоль бегущей воды, все играет, все мреет, и уже проснулось на ивах у мельницы целое общество голубых сорок.

В сопровождении человек пятнадцати пеших китайских солдат, вооруженных алебардами и несущих громадные, дурацки-яркие знамена, мы пересекли множество раз хребет по перевалам. Несмотря на середину лета, там ночью стоят такие морозы, что утром цветы подернуты инеем и становятся столь хрупкими, что ломаются под ногами с неожиданным, нежным звоном, а через два часа, лишь только обогреет солнце, вновь сияет, вновь дышит смолою и медом замечательная альпийская флора. Лепясь по крутоярам, продвигались мы под жаркой синевой; прыскали из-под ног кузнечики, собаки бежали, высунув языки, ища защиты от зноя в короткой тени, бросаемой лошадьми. Вода в колодцах пахла порохом. Деревья казались ботаническим бредом: белая с алебастровыми ягодамирябина или береза с красной корой!» [NABOKOV 200о, 304-305].

«Я видел с большой высоты темную болотную котловину, всю дрожащую от игры бесчисленных родников, что напоминало ночной небосклон с рассыпанными по нему звездами, - да так и называлась она: Звездная Степь. Перевалы поднимались за облака, переходы были тяжелые. Мы раны вьючных животных 
смазывали смесью йодоформа и вазелина. Случалось, проночевав в совершенно пустынном месте, вдруг утром видим: широким кольцом вокруг нас выросли за ночь, как черные грибы, юрты разбойников, очень скоро, однако, исчезавшие.» [NABOKOV 2000, 307].

Иногда посредством мотива дождя смываются резкие линии предметов и действительность представляется как неограниченное, подвижное многообразное существо, которое постоянно меняет свое лицо.

«В лесу, где было холодно, темно, где моросил, шелестя, слепой дождь, они оставались почему-то долго, до бессмысленно позднего часа.» [NABOKOV 200о, 234].

«Еще летал дождь, а уже появилась, с неуловимой внезапностью ангела, радуга: сама себе томно дивясь, розово-зеленая, с лиловой поволокой по внутреннему краю, она повисла за скошенным полем, над и перед далеким леском, одна доля которого, дрожа, просвечивала сквозь нее. Редкие стрелы дождя, утратившего и строй, и вес, и способность шуметь, невпопад, так и сяк вспыхивали на солнце. В омытом небе, сияя всеми подробностями чудовищно-сложной лепки, из-за вороного облака выпрастывалось облако упоительной белизны.» [NABOKOV 2000, 260-261].

Иногда реальность переходит в иллюзию и действительность представляется как обманчивая игра отражений, в которых нельзя точно определить границы между объектом и его отражением.

«Бывали и миражи, причем природа, эта дивная обманщица, доходила до сущих чудес: видения воды стояли столь ясные, что в них отражались соседние, настоящие скалы!» [NABOKOV 2000, 303-304].

Через текст романа постоянно просвечивают образы игры действительности, фантазии и иллюзии дейтвительности.

«И отец любил рассказывать, как однажды на таком закате, в 1893 году, в мертвом сердце Гобийской пустыни он повстречал, - сначала приняв их за призраки, занесенные игрою лучей, -двух велосипедистов в китайских сандалиях и круглых фетрах, американцев Сахтлебена и Аллена, невозмутимо совершавших спортивную поездку через всю Азию в Пекин.» [NABOKOV 200о, 304].

Природные мотивы образуют не только экзотическую среду, но, прежде всего, новое, только что рождающее восприятие действительности как тайны, чего-то неопределенного и постоянно меняющегося. С азиатскими мотивами открывается простор для чего-то неограниченного и расплывчатого.

«В Чанге, во время пожара (горел лес, заготовленный для постройки католической миссии), я видел, как пожилой китаец на безопасном от огня расстоянии, деловито, прилежно, без устали, обливал водой отблеск пламени 
на стенах своего жилища; убедившись в невозможности доказать ему, что дом его не горит, мы предоставили его этому бесплодному занятию.» [NABOKOV 2000, 306].

«Поднимаясь бывало по Желтой реке и ее притокам, роскошным сентябрьским утром, в прибрежных лощинах, в зарослях лилий, я с ним ловил кавалера Эльвеза, - черное чудо, с хвостами в виде копыт. Перед сном, в ненастные вечера, он читал Горация, Монтэня, Пушкина, - три книги, взятых с собой. Как то зимой, переходя по льду через реку, я издали приметил расположенную поперек нее шеренгу темных предметов, большие рога двадцати диких яков, застигнутых при переправе внезапно образовавшимся льдом; сквозь его толстый хрусталь было ясно видно оцепенение тел в плывущей позе; поднявшиеся надо льдом прекрасные головы казались бы живыми, если бы уже птицы не выклевали им глаз; и почему-то я вспомнил о тиране Шеусине, который вскрывал из любопытства беременных, а однажды, увидав как в холодное утро носильщики переходят вброд, приказал им отрезать голени, чтобы посмотреть, в каком состоянии находится мозг в костях» [NABOKOV 2000, 305-306].

Пример мимикрии как игры магических масок и игрового подражания и скрытой чудесной драмы реальности.

«Он рассказывал о невероятном художественном остроумии мимикрии, которая не объяснима борьбой за жизнь (грубой спешкой чернорабочих сил эволюции), излишне изысканна для обмана случайных врагов, пернатых, чешуйчатых и прочих (мало разборчивых, да и не столь уж до бабочек лакомых), и словно придумана забавником-живописцем как раз ради умных глаз человека (догадка, которая могла бы далеко увести эволюциониста, наблюдавшего питающихся бабочками обезьян); он рассказывал об этих магических масках мимикрии: о громадной ночнице, в состоянии покоя принимающей образ глядящей на вас змеи; об одной тропической пяденице, окрашенной в точное подобие определенного вида денницы, бесконечно от нее.» [NABOKOV 20оо, 294].

«... и о своеобразном гареме знаменитого африканского кавелера, самка которого летает в нескольких мимических разновидностях, цветом, формой и даже полетом подражающих бабочкам других пород (будто бы несъедобным), являющимся моделью и для множества других подражательниц. Он рассказывал о миграции, о том, как движется по синеве длинное облако, состоящее из миллионов белянок, равнодушное к направлению ветра, всегда на одном и том же уровне над землей, мягко и плавно поднимаясь через холмы и опять погружаясь в долины, случайно встречаясь быть может с облаком других бабочек, желтых, просачиваясь сквозь него без задержки, не замарав 
белизны, - и дальше плывя, а к ночи садясь на деревья, которые до утра стоят как осыпанные снегом, - и снова снимаясь, чтобы продолжить путь, - куда? зачем? природой еще не досказано - или уже забыто. „Наша репейница, рассказывал он, - ,крашеная дама' англичан, ,красавица' французов, в отличие от родственных ей видов, не зимует в Европе, а рождается в африканской степи; там, на заре, удачливый путник может услышать, как вся степь, блистая в первых лучах, трещит и хрустит от несчетного количества лопающихся хризалид“. Оттуда без промедления она пускается в северный путь, ранней весной достигая берегов Европы, вдруг на день, на два оживляя крымские сады и террасы Ривьеры; не задерживаясь, но всюду оставляя особей на летний развод, поднимается дальше на север и к концу мая, уже одиночками, достигает Шотландии, Гельголанда, наших мест, а там и крайнего севера земли: ее ловили в Исландии! Странным, ни на что не похожим полетом, бледная, едва узнаваемая, обезумелая бабочка, избрав сухую прогалину, „колесит“ между лешинских елок, а к концу лета, на чертополохе, на астрах, уже наслаждается жизнью ее прелестное, розоватое потомство. „Самое трогательное, - добавлял отец, - это то, что в первые холодные дни наблюдается обратное явление, отлив: бабочка стремится на юг, на зимовку, но разумеется гибнет, не долетев до тепла“.» [NABOKOV 2000, 294-295].

«Одновременно с англичанином Tutt, в швейцарских горах наблюдавшим то же, что и он на Памире, мой отец открыл истинную природу роговистого образования, появляющегося под концом брюшка у оплодотворенных самок аполлонов, выяснив, что это супруг, работая парой шпадлевидных отростков, налагает на супругу лепной пояс верности собственной выделки получающийся другим у каждого из видов этого рода, то лодочкой, то улиткой, то - как у редчайшего темно-пепельного orpheus Godunov - на подобие маленькой лиры. И как frontispiece к моему теперешнему труду мне почему-то хотелось бы выставить именно эту бабочку...» [NABOKOV 2000, 295].

С природными мотивами близки по существу мотивы пушкинские, которые вызывают подобное многообразие, подвижность и изменчивость, как и процессы природы.

«В течение всей весны продолжая тренировочный режим, он питался Пушкиным, вдыхал Пушкина, - у пушкинского читателя увеличиваются легкие в объеме. Учась меткости слов и предельной чистоте их сочетания, он доводил прозрачность прозы до ямба и затем преодолевал его...» [NABOKOV 2000, 280].

«Пушкин входил в его кровь. С голосом Пушкина сливался голос отца. Он целовал горячую маленькую руку, принимая ее за другую крупную, руку, пахнувшую утренним калачом. Он помнил, что няню к ним взяли оттуда 
же, откуда была Арина Родионовна, - из-за Гатчины, с Суйды.» [NABOKOV 2000, 280-281].

«Вот бы и преподавал то таинственнейшее и изысканнейшее, что он, один из десяти тысяч, ста тысяч, быть может даже миллиона людей, мог преподавать: например - многоплановость мышления.» [NABOKOV 2000, 344].

Все эти образы можно толковать или как носталгию, как вечную разъединенность с родным, любимым, с самим собою, и постоянное ощущение этой разъединенности. Но, с другой стороны, эти природные образы Асии поддерживают те линии романа «Дар», которые основаны на игривости, недосказанности, таинственности, неоднозначности, подвижности, метаморфозе, стихийности, непредсказанности, мноогообразности.

С одной стороны, в романе выступает серая чужбина, Берлин, человек эмигрант, беженец, конченый человек. В эту область входит и набоковское толкование Чернышевского, как чего-то однообразного, неподвижного, постоянного, рационального, организованного. С этой точки зрения, понимание действительности основано на одной общей всеохватывающей мысли. А с другой стороны, Набоков именно природыными мотивами намечает что-то постоянно уходящее, непостоянное, недосказанное, неопределенное, незаконченное, текущее, подвижное, миражное, расплывчатое. И сюда входят и образы Асии, образы отца-энтомолога, ${ }^{1}$ Зины Мерц, Пушкина и, и это надо подчеркнуть, приемы романа «Дар» в целом. Перед нами роман, представленный как подвижное существо в смысле многообразия его повествовательных форм.

Таким образом, с одной стороны оппозиции находится область механического - серого существования, черно-белого механизма, который умерщвляет всякого рода подвижность и многообразность. Перед читателем выступает линия упорядоченного, предказуемого, замкнутого в круг автоматизма. А с другой стороны оппозиции намечается образ чего-то подвижного, до сих пор не названного, стихийного, без всякого авторитета, что приводит к деавтоматизации мира ${ }^{2}$ и жизни и переносит значение к чему-то неожиданному, неизвестному. Посредством этих образов главный герой оформляет, определяет, развертывает, олицетворяет самого себя. Он виден только через образы, которые он создает. Он обрисовывает себя через образы своего искусства.

В образах Набокова действует символ, который указывает на выход образа за его собственные пределы, на присутствие некоего смысла, нераздельно слитого с образом, но ему не тождественного. Набоков ставит перед читателем

1 Ср. «мотив шага» [ALEKSANDROV 1999, 132-165]. Или об этом смотри подробнее: «фиктивная реальность» или «реальность фикции»? [ZLOČEVSKAJA 2016, 52-97].

2 Об этом смотри подробнее: Прием остранения и деавтоматизации [ŠKLOVSKIJ 1970, 20-85]. 
миражное лицо романной действительности. Здесь присутствуют и обращения к читателю, разговор с неопределенными, воображаемыми лицами, повествовательные рефлексии, чередуется повествование от 1-го и 3-го лица («я» и «не я»). Среди прозы появляются стихотворения и разного рода вставные тексты, или вообще нельзя узнать, кто говорит.

Роман «Дар» охарактеризовал в свое время В. Ходасевич: «При тщательном рассмотрении Сирин оказывается по преимуществу художником формы, писательского приема... Его произведения населены не только действующими лицами, но и бесчисленным множеством приемов, которые, точно эльфы или гномы, снуя между персонажами, производят огромную работу: пилят, режут, приколачивают, малюют... Они строят мир произведения и сами оказываются его неустранимо важными персонажами. Сирин их потому не прячет, что одна из главных задач его - именно показать, как живут и работают приемы» [CHODASEVIČ 1997, 247].

В реальности романа «Дар» выступает изменчивое лицо действительности и иллюзии действительности. И это взаимодействие действительности и фантазии и иллюзии вызвано всеприсутствующим принципом игры. И именно этот момент мы бы хотели подчеркнуть в понимании азиатских мотивов «Дара».

Чтобы преодолеть взрослый мир «чужбины» с его законченностью, устойчивостью, прочно установленными правилами, мир закономерности, рационального прагматического расчета, утилитарный мир пошлости, где человек полностью детерминирован окружающими обстоятельствами, где ему строго предопределен единственный жизненный путь, чтобы преодолеть экзистенциальную однозначность, он должен противопоставить всеохватывающе властвующему «железному» жизненному порядку равноценный противовес. Из логичности романов Набокова вытекает, что таким противовесом можно считать игру. Игра по своей сущности опирается на ничем не ограниченное проявление свободной воли индивидуума и на ничем не ограниченное творческое воображение человеческой личности. Игра является освобождением от господствующей истины и установленного порядка, она разрушает все иерархии, запреты и нормы. Игра является несомненной творческой активностью субъекта, творческим состоянием, в котором возникает новая действительность. В игре человек не подчинен сверхличной силе, а находится на ее уровне. Если можно характеризовать жизненный путь человека с детского возраста до старости как сокращение возможностей, то игра освобождает человека от непременно суживающейся перспективы, предлагает ему восстановить потерянные возможности и шансы и с помощью собственных действий убежать из этой сужающейся колеи в свободное пространство, в пространство ничем не ограниченной игры. Посредством игры человек как бы переходит 
из состояния «моно» в состояние «поли». Герой Набокова игнорирует «чужбину» и с помощью собственной творческой деятельности создает новую субъективную действительность, основанную на фантазии, интелектуальной находчивости и неограниченном воображении творца. Посредством игры набоковский герой стремится освободиться от подчиненной роли фигуры на шахматной доске, игрушки и куклы, с которыми играют и которые хотят стать «игроком», и сыграть равноценную партию с противником (спортивную с соперником, в картах со Случаем, актер в маске - с действительностью). А Набоков метит еще выше: его герои стремятся занять позицию «бога-творца», того, кто создает действительность, определяет ее правила и манипулирует всеми фигурами, следуя собственной модели мира, и заставляет все частицы подчиниться его неограниченной воле. ${ }^{3}$

Так как в мире Набокова речь идет о субъективной действительности, герои из мира утилитарной серьезности переходят в состояние игры и образуют фантазийный образ субъективной действительности, в котором они могут надевать или маску «игрока», или маску «бога-манипулятора». Посредством игры и надеванием масок перед субъектом открываются неограниченные жизненные варианты «игрока» и «творца». Таким образом, Набоков противопоставляет нормативной действительности равноценный противовес - субъективную действительность игры.

Итак, в романе «Дар» В.Набокова скрещиваются две концепции мира: одна - восходящая к прочно установленной структуре закона, иерархии и ограниченной пошлой серьезности взрослого мира, его рациональной утилитарности, авторитативности, законченности, устойчивости строгой детерминации человека в «железном» ходе обстоятельств, и другая концепция игра. Игра как прагматически немотивированная деятельность, как свободное поведение личности среди субъективной действительности, дающая многообразные альтернативы, их изменчивость, подвижность, часто иррациональные, невыгодные, как будто избыточные, ничем не мотивированные, странные поступки. Когда «детский» мир встречается с миром «взрослой» серьезности, то как бы сталкиваются два образа бытия, две концепции жизни. Антитезис «детского»и «взрослого» миров, «игры»и «серьезного» поведения можно выразить противопоставлением множества разнообразных жизненных возможностей и единого жизненного образа. «Детство» и «игра» вырастают из поливариантной основы и образуют поливариантное жизненное состояние, «взрослый» и «серьезный» мир центростремительно вращаются вокруг одного

3 Cр. «Искусство - божественная игра» [ZLOČEVSKAJA 2016, 302-481] или «феномен игры» [PECHAL 1999, 99-172]. 
заданного варианта. С маской игры герой избегает однозначности бытия и надевает экзистенциальную многозначность. Таким образом, игра является своеобразной защитой личности, сохранением «своего» в окружении пошлости чужого, одновариантного мира.

Таким образом, природные мотивы входят в ту часть образной системы романов Набокова, которые создают представление о романной действительности как о бесконечно рожадающейся многообразной альтернативе. О романе как о форме многопланового мышления, о миражах, дуализме, мимикрии, изменчивости и подвижности. Посредством принципа постоянно намекающихся и рождающихся альтернатив парадоксально соединяется вечно разъединенная и разобщенная действительность человеческого мира.

\section{Библиография:}

DOLININ, A. (2004): Tri zametki o romane Dar. In: Istinnaja žizn’ pisatelja Sirina. Sankt-Peterburg.

FICHTE, J. G. (2007): Základ všeho vědosloví. Praha.

CHODASEVIČ, V. (1997): O Sirine. In: NABOKOV, V. V.: Pro et Contra. Sankt-Peterburg. NABOKOV, V. (200o): Dar. In: NABOKOV, V.: Sobranije sočinenij russkogo perioda.

T. 4. Sankt-Peterburg, c. 188-544.

PECHAL, Z. (1999): Hra v románu Vladimira Nabokova. Olomouc.

PECHAL, Z. (2011): Fenomén živlu v ruské literatuře. Olomouc.

ŠKLOVSKIJ, V. B. (1970): Tetiva: O neschodstve schodnogo. Moskva.

TAMMI, P. (1985): Problems of Nabokov's Poetics. Narratological Analysis. Helsinki.

ZLOČEVSKAJA, A. V. (2016): Tri lika mističeskoj metaprozy XX veka: German GesseVladimir Nabokov - Michail Bulgakov. Sankt-Peterburg.

\section{About the author}

Zdenĕk Pechal, Palacký University Olomouc, Faculty of Arts, Department of Slavonic Studies, Olomouc, Czech Republic,zdenek.pechal@upol.cz 
